Research Article

\section{Case-based education to improve learning and faculty teaching of residents and students in a clinical setting}

\author{
Elizabeth A Wetzel ${ }^{1}$ and Diane E Lorant ${ }^{2 *}$ \\ 'MD, Assistant Professor, Department of Pediatrics, Indiana University School of Medicine, \\ Associate Neonatal-Perinatal Fellowship Director, USA \\ ${ }^{2} \mathrm{MD}$, Associate Professor, Department of Pediatrics, Indiana University School of Medicine, USA
}

\section{Abstract}

Introduction: Current pediatric residents spend less time in the neonatal intensive care unit (NICU) and as a result, resident exposure to neonatal pathophysiology has decreased. Engaging learners efficiently while balancing clinical demands is challenging. Practices to enhance adult education include integration of problem centered learning into the demands of daily life in an environment in which learners feel safe asking questions and expressing themselves.

Methods: With this principal in mind, we developed a curriculum to enhance resident and medical student education during busy NICU rotations. The curriculum was case-based, available on-line and facilitated by neonatology faculty and fellows. A template designed to be concise and interactive was used to create and present the cases. After the case vignette, the template prompted medical students and residents to generate a differential diagnosis, order a diagnostic workup and narrow the diagnosis. Discussion of the diagnoses occurred at the conclusion of the cases; however, the template discouraged didactic lectures.

Results: In two years, cases were viewed 2,362 times. Facilitators and learners rated the quality and utility of the cases favorably overall. Cases took approximately 20 minutes to complete. Approximately $57 \%$ of survey respondents reviewed $1-2$ cases per week and $9.6 \%$ reviewed 3-5 cases per week.

Discussion: A template with a concise and consistent format to construct and present cases allows for the creation of a curriculum that can be incorporated into a clinically demanding service and may enhance clinical teaching and learner engagement.

\section{More Information}

*Address for Correspondence: Diane E Lorant MD, Associate Professor, Department of Pediatrics, Indiana University School of Medicine USA, Tel: (317) 274-4715; Email: dlorant@iu.edu

\section{Submitted: 23 January 2020 \\ Approved: 04 February 2020 \\ Published: 05 February 2020}

How to cite this article: Wetzell EA, Lorant DE. Case-based education to improve learning and faculty teaching of residents and students in a clinical setting. J Adv Pediatr Child Health. 2020; 3: $011-015$

DOI: dx.doi.org/10.29328/journal.japch.1001010 ORCiD: orcid.org/0000-0002-3248-7568

Copyright: (c) 2020 Wetzell EA, et al. This is an open access article distributed under the Creative Commons Attribution License, which permits unrestricted use, distribution, and reproduction in any medium, provided the original work is properly cited.

Check for updates

OPEn ACCESS

\section{Introduction}

Education of resident physicians in newborn intensive care has changed dramatically over the past two decades. In 1996, the Accreditation Council for Graduate Medical Education (ACGME) limited the amount of time residents could spend taking care of pediatric and neonatal intensive care patients to 6 months of their 3-year residency, including daytime rotations and night call. This was followed by duty hour restrictions in 2003, which became even more restrictive in 2011 [1,2]. As a result, contemporary pediatric residents spend considerably less time in the newborn intensive care unit (NICU) than they did 25 years ago. Implementation of the ACGME regulations has led to replacement of the resident work force with advanced practice providers including neonatal nurse practitioners and physician assistants [3]. Although the ACGME regulations were created to enhance patient safety and resident wellbeing, decreased resident time in the NICU restricts their breadth of exposure to neonatal pathophysiology.

Duty hour restrictions have also brought about significant decreased resident attendance at mock resuscitations, grand rounds and didactic lectures [4]. According to Bloom's revised taxonomy of the cognitive process, learning progresses through a series of stages beginning with basic knowledge and comprehension. Learners then sequentially progress through the more advanced stages of application, analysis, evaluation and creation [5]. The highest level of learning obtained during 
didactic lectures are knowledge and comprehension. Contrary to passive learning during didactic lectures, analyzing clinical cases encourages the use of an active and inquiry-based learning method. Case-based learning allows learners to apply their knowledge in the analysis and evaluation of cases, enhancing their critical thinking. Clinical decision making by fourth-year dental students was enhanced by attending small group discussions of clinical cases. At the conclusion of the academic year, the dental students were evaluated with a Structure of Observed Learning Outcome (SOLO) taxonomy. SOLO taxonomy measures learning from prestructural (define, identify) through extended abstract (evaluate, generalize, predict, create, hypothesize, reflect). Students who attended the case-based discussions had significantly higher scores in the higher mental order tasks of the SOLO compared to students only attending traditional lectures [6]. This study demonstrated advanced critical thinking skills in the group that attended case-based discussions. However, assessment of basic knowledge without an evaluation of critical thinking has not consistently shown superiority of case-based education compared to traditional lectures. USMLE scores for medical students taught with a problembased curriculum did not differ significantly from those taught with a standard curriculum [7]. Third year veterinary students were randomly assigned to case-based instruction or a traditional lecture-based instruction. Students took identical multiple-choice examinations at 1 week and again at 4 months after completion of the course. The overall exam scores were not statistically different between the groups at either time. However, the students in the case-based learning group scored higher on the more difficult questions, perhaps reflecting their increased clinical reasoning and problem solving [8]. In these studies, the benefit of better critical thinking skills maybe offset by the decreased material covered in problem-based or case-based education [9].

Although the data on the effectiveness of case-based learning compared to a traditional lecture series is variable, students overwhelmingly prefer case-based learning [10]. Case-based learning has been shown to be an efficient method of disseminating information in situations with time constraints [8], such as during a busy clinical rotation. It is especially amenable to small group discussion as would occur amongst a medical team. Utilizing authentic clinical cases expands the breadth of patient presentations beyond the limited number of patients that residents and medical students may encounter on a clinical rotation. A literature review on case-based education concluded that "human cases impart relevance and aid in connecting theory to practice" [11].

\section{Methods}

A multidisciplinary education workgroup comprised of neonatologists, neonatology fellows and neonatal advanced practice providers convened with the goal of enhancing resident and student education in the NICU. The workgroup completed a strengths, weakness, opportunities, threats (SWOT) analysis on the current state of education in the NICU. The SWOT analysis identified an inconsistent approach to teaching and a sense of urgency to complete "work rounds" as threats to education.

In response to the SWOT analysis, the workgroup developed a series of educational cases to facilitate teaching neonatal pathophysiology. All cases were similarly formatted in PowerPoint to enhance teaching consistency (Appendix A). The authors of the cases were able to add notes to the presenter view, making it easier for fellows or faculty to utilize the cases without significant advanced preparation. The template was designed to be concise and foster interactive discussions. Learners have to generate a differential diagnosis and request a diagnostic workup. As the cases unfold, learners have to narrow the diagnosis. At the conclusion, there are questions about the case to generate discussion on the management plan. Case facilitators were instructed to have an interactive dialogue with learners to help keep them on track with their analysis of the case. The goal was that individual case discussions be completed within the peak-adult attention span of 20 minutes [12]. Authors of cases were able to pick a neonatology topic of their choice that was appropriate for medical student/resident level of learning. Each case had American Board of Pediatric knowledge specifications identified at the conclusion.

The education work group invited neonatology faculty, fellows and advance practice providers to write the clinical cases. The work group used several methods to encourage fellows and faculty to submit cases:

1) The administrative assistant of the education work group contacted faculty and fellows who had given previous didactic lectures to request that they develop a case discussion from the content of their presentations.

2) Faculty earned 25 part IV Pediatric Maintenance of Certification credits if they wrote at least two cases per a year, peer reviewed cases, and attended at least two meetings of the education work group per year.

3) The number of cases written per year was taken into account when calculating the faculty merit-based bonus given by the division.

4) Fellows were asked to write two cases per year as part of their academic teaching requirements.

Authors submitted their completed cases to the education work group. Each completed case was peer reviewed by two members of the work group. Following peer review, the cases went back to the original authors for final editing. Once the cases were finalized they were categorized based on systems (pulmonary, cardiology etc.) and uploaded to a specified folder 
in an institutional cloud storage system. Since the curriculum was available on an institutional shared website, we were able to track the number of times the cases were accessed.

To encourage using the cases as a teaching tool, the education workgroup administrative assistant sent an e-mail to each fellow and faculty at the beginning of their clinical rotation with directions on accessing the cases in the shared folder and asked that they review at least two cases per week with learners. Learners included all medical students and residents that were on a neonatology rotation in one of three NICUs, which encompass levels of medical care II, III and IV. At the conclusion of the rotation, fellows and faculty received an electronic survey regarding their assessment of the cases (Appendix B). Medical students and residents received a different survey about the cases at the conclusion of their neonatal rotation (Appendix C).

\section{Results}

Case-based education began in July 2017 and the data was analyzed through July 2019. Within 2 years of beginning casebased education, there have been 59 cases uploaded to the neonatology-shared folder with 2,362 views of those cases. During this period, 232 medical students/residents and 280 fellows/faculty received a survey about how often they used the cases and their assessment of the utility and quality of the cases.

There were 165 respondents to the medical student/ resident survey ( $71 \%$ completion rate). In response to a question about the average number of cases per week they reviewed with either a fellow or faculty, $1.8 \%$ reviewed $>5$ cases, $9.6 \%$ reviewed $3-5$ cases, and $57.4 \%$ reviewed $1-2$ cases. The remaining $38.8 \%$ reviewed $<1$ case per week, however all but four had sufficient exposure to the cases to complete the survey. The majority of medical students and residents indicated that the cases expanded their knowledge of neonatology and met their professional expectations and needs. Medical students and residents also felt that the cases were up to date and translated evidence into practice (Figure 1).

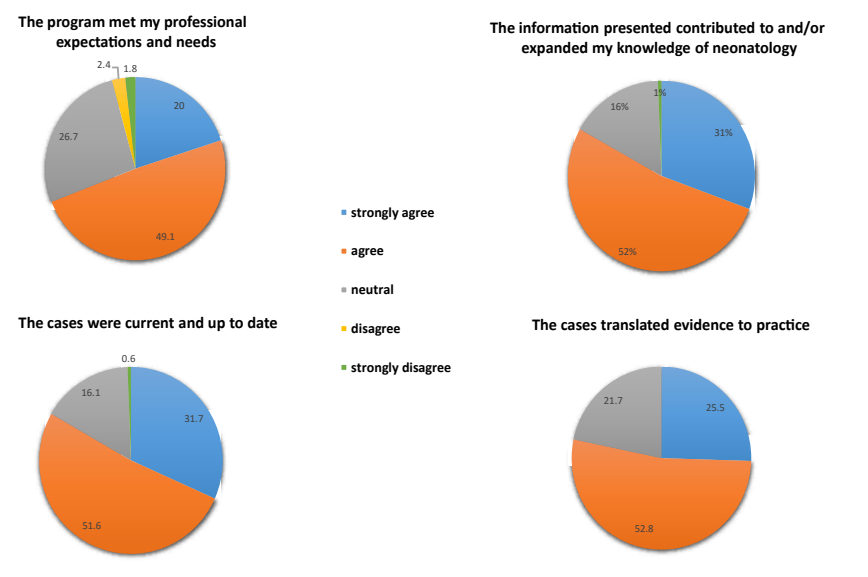

There were 115 respondents to the fellow/faculty survey ( $42 \%$ completion rate). The average number of cases they facilitated per week was very similar to that reported by the medical students and residents $(33 \%<1$ case, $57.4 \% 1-2$ cases and 9.6\% 3-5 cases). Just over half of the facilitators (51\%) were able to complete the case-based education within the intended 20 minutes. The remainder (44.3\%) completed the cases in $20-30$ minutes. Only $4.4 \%$ of faculty/fellows reported that on average the cases took more than 30 minutes to facilitate. Faculty and fellows indicated that the cases are easy to access on the neonatology-shared drive and found case topics relevant to what they wanted to teach. They also report that the cases were engaging, interactive and an effective way to incorporate education into service (Figure 2).

Both groups of respondents gave a favorable overall rating of the cases, although the assessment by faculty and fellows was more favorable than that of the medical students and residents (Figure 3). Fellows and faculty had the opportunity to complete a free text question about the barriers to using the cases to teach during their NICU rotation. A common barrier identified by $70 \%$ of fellows and faculty was finding the time to review the cases. They indicated that the time barrier was due to high census, high acuity and limited resident availability due to outpatient clinics and the post-call resident leaving after morning rounds. Conversely, only $8 \%$ of medical students and residents indicated that there was insufficient time to review the cases. Medical student and resident comments indicated some frustration that a fellow or faculty had not gone over more cases with them during the rotation. They indicated that
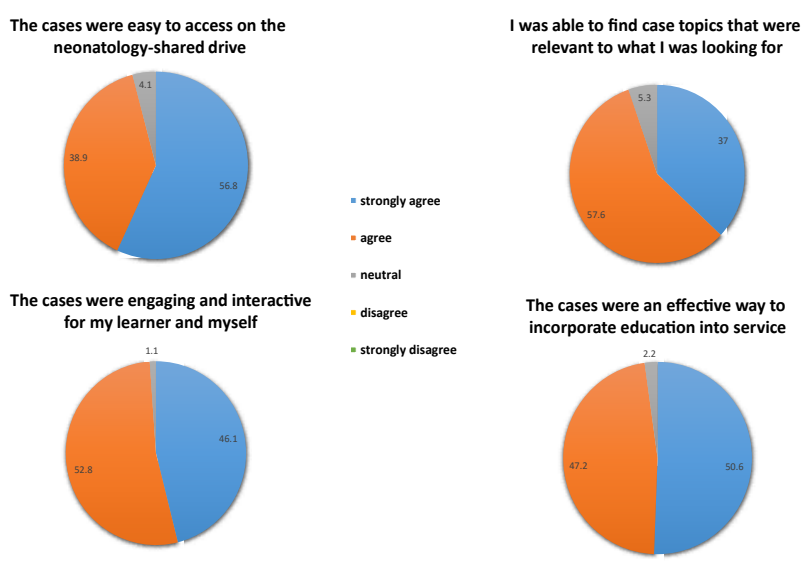

Figure 2: Faculty/fellow survey responses.

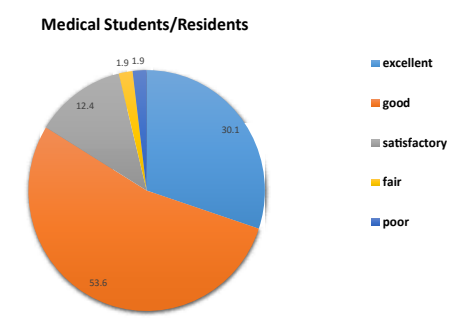

Faculty/Fellows

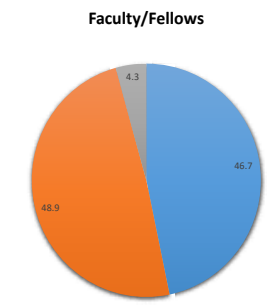

Figure 3: Overall evaluation of the cases. 
the number of cases reviewed was more dependent on which fellow or faculty was on service rather than the perceived competing clinical demands of the rotation. There were many medical student/resident comments endorsing case-based learning and appreciating the concise presentation of the cases.

Although the cases were developed to enhance student and resident knowledge and analytical practice of neonatology, implementation of the curriculum has not been sufficiently consistent to measure an improvement in knowledge or skills. Resident evaluation of the overall NICU rotation experience has not changed significantly since implementation of casebased learning.

\section{Discussion}

The template that we developed (Appendix A) utilizes a case-based education format. The case template is not specific to neonatology and can be used to generate case-based discussion in any field of medicine. The benefit of the template is that each case is formatted the same so that facilitators know what to expect when they utilize the cases to teach. Slide notes enable facilitators to review the cases with little to no advanced preparation. The template encourages learners to generate a differential diagnosis and management plan so that the presentation does not digress into a didactic lecture. The format was effective in limiting the time to discuss the cases, allowing fellows and faculty to integrate the cases to supplement bedside teaching. The 2,362 views of the cases in two years is a testament to their perceived educational value.

The curriculum met our stated educational objectives for this project. A curriculum has been previously published that utilizes case vignettes in neonatology to evaluate knowledge gained from an evidence-based medicine curriculum [13]. Conversely, we designed our case-template to develop brief and interactive cases, which will supplement learning from patient encounters. Facilitators were able to explain neonatal pathology utilizing case based education. According to the faculty and fellows surveyed, the cases were engaging, interactive and an effective way to incorporate education into service. Requiring each case to have American Board of Pediatric knowledge specifications identified at the conclusion assured that the material would be timely, evidence based and pertinent to the medical students and residents. The overall assessment of the cases by faculty, fellows, medical students and residents was very positive.

As with any survey, a limitation is the number of nonresponders to the survey. The $71 \%$ response from medical students and residents should give a reasonable assessment of their experience. However, only $42 \%$ of the fellows and faculty responded to the survey. The poor response from faculty may be because only half of the faculty surveyed were on a resident team. All faculty were encouraged to use the cases for teaching, however faculty without daily interaction with residents had less incentive to utilize the cases. Alternatively, faculty or fellows may have felt uncomfortable with casedbased education. Medical schools utilizing problem-based education have reported difficulty recruiting trained faculty to facilitate case discussion [7]. We did not assess fellow or faculty skill in facilitating case discussions.

Although the cases met our goal of brief educational sessions of approximately 20 minutes, finding time to review cases with medical students and residents continued to be a major barrier. Initially only fellows and faculty had access to the cases because our intention was to have faculty or fellows guide the learners through the cases. However, since medical students and residents expressed frustration with variable access to cases, after July 2019, we gave residents access to the cases. Now senior residents can use the cases as a tool to teach more junior residents and medical students. The education workgroup is currently working on trouble shooting the time barrier reported by faculty and fellows. One solution is to replace some of our didactic sessions with these shorter case-based discussions rather than adding the cases to an already heavy workload. We also plan to trial an education "snack break" with snacks brought in to entice the team to take a break and review a case. Once the cases are utilized more consistently, we plan to evaluate the impact on the neonatology portion of the resident in-training exam and resident teaching evaluations.

In summary, a multi-professional education work group successfully designed a case based curriculum that supplemented the educational efforts of faculty and fellows in the neonatal intensive care unit. The template created is not specific to neonatology and is relevant as a supplement to bedside teaching for learners in any field of medicine.

\section{Acknowledgment}

The education work group would like to thank Sarah Worrell and Alyssa Cougill for their administrative assistance.

The education work group in the section of PerinatalNeonatal Medicine at Indiana University sponsored this project.

\section{References}

1. Pastores SM, O'Connor MF, Kleinpell RM, Napolitano L, Ward N, et al. The Accreditation Council for Graduate Medical Education resident duty hour new standards: history, changes, and impact on staffing of intensive care units. Crit Care Med. 2011; 39: 2540-2549.

PubMed: https://www.ncbi.nlm.nih.gov/pubmed/21705890

2. Kaufman DM. Applying educational theory in practice. BMJ. 2003; 326: 213-216.

PubMed: https://www.ncbi.nlm.nih.gov/pubmed/12543841

3. Moote M, Krsek C, Kleinpell R, Todd B. Physician Assistant and Nurse Practitioner Utilization in Academic Medical Centers. Am J Med Qual. 2019; 34: 465-472.

PubMed: https://www.ncbi.nlm.nih.gov/pubmed/21555487 
4. DeLaroche A, Riggs T, Maisels MJ. Impact of the new 16-hour duty period on pediatric interns' neonatal education. Clin Pediatr (Phila). 2014; 53: 51-59.

PubMed: https://www.ncbi.nlm.nih.gov/pubmed/24002047

5. Krathwohl DR. A Revision of Bloom's Taxonomy: An Overview. Theory Into Practice. 2002; 41: 212-218.

6. Ilguy M, Ilguy D, Fisekcioglu E, Oktay I. Comparison of case-based and lecture-based learning in dental education using the SOLO taxonomy. J Dent Educ. 2014; 78: 1521-1527.

PubMed: https://www.ncbi.nlm.nih.gov/pubmed/25362693

7. Distlehorst LH, Dawson E, Robbs RS, Barrows HS. Problem-based learning outcomes: the glass half-full. Acad Med. 2005; 80: 294-299. PubMed: https://www.ncbi.nlm.nih.gov/pubmed/15734816

8. Grauer GF, Forrester SD, Shuman C, Sanderson MW. Comparison of student performance after lecture-based and case-based/problembased teaching in a large group. J Vet Med Educ. 2008; 35: 310-317. PubMed: https://www.ncbi.nlm.nih.gov/pubmed/18723821
9. Berkson L. Problem-based learning: have the expectations been met? Acad Med. 1993; 68: S79-88.

PubMed: https://www.ncbi.nlm.nih.gov/pubmed/8216642

10. Thistlethwaite JE, Davies D, Ekeocha S, et al. The effectiveness of casebased learning in health professional education. A BEME systematic review: BEME Guide No. 23. Med Teach. 2012; 34: e421-444. PubMed: https://www.ncbi.nlm.nih.gov/pubmed/22578051

11. McLean SF. Case-Based Learning and its Application in Medical and Health-Care Fields: A Review of Worldwide Literature. J Med Educ Curric Dev. 2016; 3.

PubMed: https://www.ncbi.nlm.nih.gov/pubmed/29349306

12. Bradbury NA. Attention span during lectures: 8 seconds, 10 minutes, or more? Adv Physiol Educ. 2016; 40: 509-513.

PubMed: https://www.ncbi.nlm.nih.gov/pubmed/28145268

13. Pammi M, Lingappan K, Carbajal MM, Suresh GK. Focused EvidenceBased Medicine Curriculum for Trainees in Neonatal-Perinatal Medicine. MedEdPORTAL. 2017; 13: 10664.

PubMed: https://www.ncbi.nlm.nih.gov/pubmed/30800864 